\title{
Stochastic Time Series Prediction Equation Using Wavelet Packets for Iran
}

\section{Habib Rahimi ( $\nabla$ rahimih@ut.ac.ir)}

University of Tehran Institute of Geophysics https://orcid.org/0000-0002-2085-1043

\section{G. Tanircan}

Bogazici Universitesi

Mohammad Shahvar

BHRC: Building and Housing Research Center

\section{Research Article}

Keywords: Stochastic Time series Prediction Equation, Wavelet Packets, Strong motion, Iran.

Posted Date: July 26th, 2021

DOI: https://doi.org/10.21203/rs.3.rs-620756/v1

License: (1) This work is licensed under a Creative Commons Attribution 4.0 International License. Read Full License 


\title{
Stochastic Time series Prediction Equation Using Wavelet Packets for Iran
}

\author{
Mohammadreza najaftomaraei ${ }^{1}$, Habib Rahimi $^{2}$, G. Tanircan ${ }^{3}$, Mohammad Shahvar $^{4}$ \\ 1) $\mathrm{PhD}$ student, Institute of geophysics, University of Tehran, Tehran, Iran (najaftomraei@ut.ac.ir) \\ 2) Associate Professor, Institute of geophysics, University of Tehran, Tehran, Iran (rahimih@ut.ac.ir) \\ 3) Associate Professor, Kandilli Observatory and Earthquake Research Institute, Bogazici University, Istanbul, Turkey \\ (birgore@boun.edu.tr) \\ 4) Assistant Professor, Building \& Housing Research Center (BHRC), Tehran, Iran, (m.shahvar@bhrc.ac.ir)
}

\section{Abstract}

In this study, a stochastic simulation model proposed by Yamamoto and Baker (2013), is applied to Iranian strong motion database which comprises more than 3828 recordings for a time period between 1975-2018. Each ground motion is decomposed into wavelet packets. Amplitudes of wavelet packets are divided into two groups and for each group model parameters are estimated using the maximum likelihood method. Regression coefficients are then obtained relating model parameters to seismic characteristics such as earthquake magnitude, distance, and site condition. Inter-event residuals of coefficients and correlation of total residuals of those parameters are also calculated. To reconstruct the amplitudes in time domain and do the simulation, inverse wavelet packet transform is used. Finally, a validation test is performed. The comparison of ground motion intensity measures for recorded and simulated time series shows an acceptable conformity in the application. The estimated parameters using the simulated data are in good agreement with the real data, indicating the acceptable validity of the estimated stochastic simulation model. Obtained regression equations can be used to generate ground motions for the future earthquake scenarios in Iran.

Keywords: Stochastic Time series Prediction Equation; Wavelet Packets; Strong motion; Iran.

\section{Introduction}


Iranian plateau is located on the Alpine-Himalayan orogenic belt and due to the northward motion of the Arabian plate toward Eurasia it continuously deforms. Most of this deformation occurs mainly in the Alborz, Kopeh Dagh, and Zagros Mountains (Fig. 1a). Except the Makran subduction zone to the southeast of Iranian Plateau, where an oceanic lithosphere subducts northward under southeast Iran (Nilforoushan et al. 2003), continental form of the ArabianEurasian plates' convergence causes the present tectonics of Iran (Jackson and McKenzie, 1984) that results in tectonically complex region with structures different in density, velocity, etc. The Iranian plateau is noticed as one of the very seismically active areas of the world. The 1909 Silakhor (Mw:7.4), the 1962 Buin Zahra (Mw:7.2); the 1972 Gir (Mw:6.7); the 1978 Tabas (Mw:7.4); the 1990 Manjil-Rudbar (Mw:7.4); the 2003 Bam (Mw:6.6); the 2012 Ahar-Varzaghan (Mw:6.4) and the 2017 Ezgeleh (Mw:7.3) earthquakes are among the most destructive ones occurred yet. Active seismic sources, young tectonics and convergence rate due to regional and global tectonics caused major earthquakes with large destructions and casualties in the last 50 years in Iran, where there are many populated industrial cities with critical infrastructures. This depicts a critical need for seismic risk assessment and its mitigation tools.

Strong ground motion recordings have indispensable role in earthquake engineering for investigating individual characteristics of the earthquakes and response of structures under excitation. Structural design spectra in almost all seismic regulations are formed utilizing strong ground motion intensity measures (GMIM, e.g., Peak Ground Acceleration, PGA) as well as spectral quantities (e.g., Spectral Acceleration, SA) calculated through hazard assessments. Assessments are essentially done utilizing ground motion prediction equations (GMPE) compatible for a specific region. Hence precise calculation of GMPE is directly dependent to the amount of strong motion recordings in a region. Strong motion simulation techniques are convenient ways to produce abundant ground motions as an input for structural analysis in earthquake engineering, especially for the regions that will be urbanized and that lack of enough strong motion data. In addition to that, synthetic accelerograms provide demand parameters of earthquake engineers which can be extracted from them and are allowed in several design regulations for nonlinear time history analyses of structures. Generating synthetic ground motions whose features matches with the characteristics of the recorded ground motions can be a substitute approach. 
There have been several works on ground motion simulation of earthquakes in Iran. Among them, Nicknam et al, 2007 present a probabilistic-based strong motion compatible with the source-path and site soil condition given the probability of exceedance for citadel of Arg-e-Bam site bed rock. Soghrat et al, 2011, developed a GMPE for soil and rock sites in northern Iran, based upon the calibrated specific barrier model (SBM) against the latest available strong motion data. Hassani et al, 2012, implemented stochastic finite-fault modeling based on dynamic corner frequency to simulate the 22 February 2005 (Mw 6. 4) Zarand Earthquake. Zafarani and Soghrat, 2012, have developed a physically-based GMPE for soil and rock sites in the Zagros region based on the SBM. Zafarani, 2013 used a hybrid simulation method to calculate broadband ground-motion time histories at bedrock level for deterministic earthquake scenarios on the NTF. Gholami et al, 2013, used a hybrid technique to simulate the ground motion caused by an earthquake with $\mathrm{Mw}=4$, which occurred close to Tehran, 17 October 2009, and is the first local earthquake that has ever been recorded by the local strong ground motion network in Tehran. Gholami et al, 2013, applied new analytical methodology for computing synthetic seismograms in 3-D anelastic media to the modelling of the local records of the 2003 Bam Mw 6.6 earthquake, Southeastern Iran. Zafarani et al, 2015, employed a generalized inversion of S-wave amplitude spectra for deriving the site response and S-wave attenuation (quality factor) in the northwest region of Iran. Riahi et al, 2015, simulated the 2003 Bam earthquake acceleration recordings at three strong-motion stations by the empirical Green's function method. Vahidifard et al, 2017, presented a simulation of three components of near-field ground shaking recorded during the main shock at three stations of the September 16, 1978, Tabas (M w = 7.4), Iran, using a hybrid method (composed of discrete wavenumber method) and a stochastic finite-fault modeling based on a dynamic corner frequency.

The literature review about several models of earthquake ground motion construction that has been done by O’ lafsson et al. (2001) and Douglas et al. (2008) show that all those techniques can be basically categorized in three groups: 1 . The deterministic approach: in this method, the model is based on physical principles. This approach produces ground motions by modeling of those parameters that affects the shape, the duration and frequency content of them (e.g., Hanks 1979, Hanks and McGuire 1981, Boore 1983, Silva et al. 1999, Atkinson and Somerville 1994, Boore 2003, Atkinson and Boore 2007, Pitarka et al., 1998). 2. The empirical or the stochastic simulations that are based on the assumption that future scenarios will be akin to that observed earlier events 
and so try to match with target seismological and probabilistic features (e.g., Campbell 1986, Joyner and Boore 1988, Baker and Cornell 2006, Watson-Lamprey and Abrahamson 2006, Abrahamson and Shedlock 1997, Anderson 1997b, Lee et al. 2000, Douglas 2003, Scherbaum et al. 2004, Bommer and Alarc'on 2006, Power et al. 2008, Abrahamson et al. 2008). 3. Hybrid approaches that combine factors of both (e.g., Campbell 2003, Tavakoli and Pezeshk 2005, Douglas et al. 2006, Scherbaum et al. 2006, Campbell 2007, Pitarka et al. 2000, Hartzell et al. 2002, Mai and Beroza 2003, Hisada 2008).

Some of the important issues about above-mentioned studies are: 1. Researchers performed ground motion simulations of a specific earthquake, not for a region or even not for whole country 2. GMPEs generally predict a special ground motion parameter (e.g., PGA, SA) not all the time stories 3. GMPEs predict ground motions at different frequencies with indeterminate time 4. The mentioned researches don't consider nonstationarity. As it is known temporal and spectral nonstationarity (changing amplitudes and changing frequency characteristics of time series, respectively) can have effects on nonlinear dynamic structural response.

Hence methods that are able to reproduce nonstationary characteristics of ground motions is needed.

Amiri et al, 2011, predicted the amplitudes of wavelet packet coefficients using neural network approach. Their simulations do not consider any seismological parameters such as source, path and site effects, so ground motions which can contain all available variables of possible future earthquakes generated with their models is rather difficult.

Discrete Wavelet Transform (DWT) is another approach to generate synthetic ground motions (e.g., Sasaki et al, 2003, Bai et al, 2012), however, time localization of low frequency amplitudes is the issue in DWT.

Yamamoto and Baker, 2013 (hereafter, YB2013) have proposed a stochastic method which uses wavelet-packet transform (WPT) to describe the waveform in the time and frequency domain and finally simulates time series using inverse wavelet transform. The reasons of selecting Wavelet Packet Transform (WPT) among wavelet analysis approaches, are the following items: 1. Because of nonorthogonality of the wavelets at neighbor times and frequencies, reconstructing time series using the Continuous Wavelet Transform (CWT) is complicated. 2. time localization of low frequency amplitudes is the issue in DWT as mentioned above. 3. controlling resolution in the time and frequency domains in WPT, a developed copy of the DWT, is easier which basis functions are 
121 orthogonal, making it easy to reconstruct time series. 4. Simulated ground motions resulting from

122 their proposed stochastic ground-motion model are variable, because it has an effect on the 123 variability of structural responses (e.g., Rezaeian and Der Kiureghian, 2010, 2012). YB2013

124 method have been successfully applied to strong motion data at various part of the world. Among 125 them Huang and Wang, (2015) Huang and Wang, used wavelet packets and cokriging analysis to stochastically simulate spatially distributed ground motions over a region.

127 Stochastic simulations, in general require fewer parameters and are computationally less expensive 128 than physics-based and hybrid simulations but they don't consider physical phenomena because there are almost no parameters in the stochastic model to control these effects. The method proposed by YB2013 overcomes this problem. Unlike the previous works that simulate a specific earthquake, this method can be applicable to a tectonic region. In addition to that, previous GMPEs have capability to estimate only GMIMs but YB2013 predicts the whole time series, and unlike the previous studies, this approach locates the frequencies in time and also considers temporal and spectral nonstationarity.

135 136

Considering the above discussed superiority of the YB2013 over conventional stochastic methods, YB2013 method is utilized for the simulation of the substantial strong ground motion recordings in Iran. The motivation of this study comes from the fact that no work is available predicting ground motion time series in a robust way for Iran with a large strong ground motion database.

We begin this paper by introducing the general procedure of YB2013. Then procedure is extended to Iranian strong ground motion data. Finally, comparison of GMIMs of simulated versus recorded strong ground motion and SA at various period is performed for validation the approach.

\section{Methodology}

YB2013 proposed a stochastic simulation method which uses wavelet-packet transform to describe the waveform in the time and frequency domain and to simulate time series using inverse wavelet transform. Major advantage of this methods is that it does not necessitate a detailed information on the source rupture process, propagation path and local site effects, while success of the physics based and hybrid simulation techniques directly depends on potential to characterize those fundamental inputs. Fewer parameters are needed for the YB2013 stochastic simulation method and in comparison, to physics-based and hybrid simulations, they are computationally less expensive. 13 parameters are requisite in their proposed model that can be obtained by regression 
151

152

153

154 155

$$
\left|c_{j, k}^{i}\right|^{2}=\left|c_{j, k, \text { maj }}^{i}\right|^{2}+\left|c_{j, k, \min }^{i}\right|^{2}
$$

$$
c_{j, k}^{i}=\int_{-\infty}^{\infty} x(t) \psi_{j, k}^{i} d t
$$
$0.02 \mathrm{~s}$ and 8 respectively. total wavelet packet coefficients: respectively.

analysis which comprises proper variability matching with the properties of the simulated ground motions. PGA, Arias intensity (Arias, 1970), and significant duration (Trifunac and Brady, 1976) of simulated ground motions obtained by the model and those of recorded ground-motion was compared and the results showed a relatively appropriate agreement.

In the following, steps of stochastic simulation model introduced by YB 2013 are summarized. Total scheme of their stochastic modeling is also shown in Figure 3.

\section{2a. Decomposing time series using Wavelet Packet Transform}

In the first step the coefficients of wavelet packets have been obtained. In order to decompose a ground-motion time series into wavelet packets in the time and frequency domain, WPT was employed and it is defined as follows:

where $x(t)$ is the time series, $c_{j, k}^{i}$ is the WPT coefficients in which i is its location in the frequency axis, $\mathrm{j}$ is the scale parameter number that shows frequency resolution and $\mathrm{k}$ is its location in the time and $\psi_{j, k}^{i}$ is the wavelet packet function. The mother wavelet function used here is Meyer wavelet (Meyer, 1986), because it has orthogonality characteristic and right positioning in both the time and the frequency axis and is computed from the finite-impulse response-based approximation. To minimize the residual of simulated data, wavelet packets in the lowest frequency (as low as $0.1 \mathrm{~Hz}$ ) level had to be controlled, to this done the $\mathrm{dt}$ and $\mathrm{j}$ is selected to be

\section{2b. Dividing wavelet packet coefficient into two groups of Major and Minor}

Amplitudes of WPT were divided into two groups, major (that contains $70 \%$ of the total energy) and minor, because WPT have few coefficients with large amplitudes (less than $1 \%$ of the total number of wavelet packet coefficients). These two groups are united as follows to obtain the

where $c_{j, k, m a j}^{i}$ and $c_{j, k \text { min }}^{i}$ are the coefficients of wavelet packet in the major and minor groups, 
178 The energy fraction criteria maximize the difference of the characteristics of wavelet packet 179 coefficients of the major and minor groups.

\section{2c. Finding Parameters for both Major and Minor group}

The 13 parameters that explains the time and frequency characteristics of the acceleration time series are given in Table 1. Equation 3 is obtained for the whole amplitudes (major and minor group), equation 4-14 is obtained for two groups separately, equation 14 is obtained for just major group. Note that the 13th parameter is which is standard deviation of (i.i.d. lognormal random variables with median one and logarithmic standard deviation of the residual of the wavelet packets in the minor group computed from the bivariate lognormal function). In both groups the correlations between time and frequency are transformed to a new parameter using cumulative density function of the standard normal distribution and is called transformed coefficient because it is more appropriate for prediction using regression analysis

$$
\begin{aligned}
& E_{a c c}=\sum_{i} \sum_{k}\left|C_{j, k}^{i}\right|^{2} \\
& E(t)_{m a j}=\sum_{i} \sum_{k} t_{i, k_{m a j}}\left|C_{j, k_{m a j}}^{i}\right|^{2} / E_{a c c} \\
& E(t)_{\min }=\sum_{i} \sum_{k} t_{i, k_{\min }}\left|C_{j, k_{\min }}^{i}\right|^{2} / E_{a c c} \\
& S^{2}(t)_{m a j}=\sum_{i} \sum_{k}\left\{t_{i, k_{m a j}}-E(t)_{\min }\right\}^{2}\left|C_{j, k \text { maj }}^{i}\right|^{2} / E_{a c c} \\
& S^{2}(t)_{\min }=\sum_{i} \sum_{k}\left\{t_{i, k_{\min }}-E(t)_{\min }\right\}^{2}\left|C_{j, k_{\min }}^{i}\right|^{2} / E_{a c c} \\
& E(f)_{m a j}=\sum_{i} \sum_{k} f_{i, k_{m a j}}\left|C_{j, k_{m a j}}^{i}\right|^{2} / E_{a c c} \\
& E(f)_{\min }=\sum_{i} \sum_{k} f_{i, k_{\min }}\left|C_{j, k_{\min }}^{i}\right|^{2} / E_{a c c} \\
& S^{2}(f)_{m a j}=\sum_{i} \sum_{k}\left\{f_{i, k_{m a j}}-E(f)_{m a j}\right\}^{2}\left|C_{j, k_{m a j}}^{i}\right|^{2} / E_{a c c} \\
& S^{2}(f)_{\min }=\sum_{i} \sum_{k}\left\{f_{i, k_{\min }}-E(f)_{\min }\right\}^{2}\left|C_{j, k \min }^{i}\right|^{2} / E_{a c c} \\
& \rho(t, f)_{m a j}=\frac{\sum_{i} \sum_{k}\left[t_{i, k_{m a j}}-E(t)_{m a j}\right]\left[f_{i, k_{m a j}}-E(f)_{m a j}\right]\left|C_{j, k_{m a j}}^{i}\right|^{2}}{S(t)_{m a j} S(f)_{m a j} E_{a c c}} \\
& \rho(t, f)_{\min }=\frac{\sum_{i} \sum_{k}\left[t_{i, k_{\min }}-E(t)_{\min }\right]\left[f_{i, k_{\min }}-E(f)_{\min }\right]\left|C_{j, k_{\min }}^{i}\right|^{2}}{S(t)_{\min } S(f)_{\min } E_{a c c}} \\
& E(a)_{m a j}=\sum_{i} \sum_{k}\left|c_{j, k_{m a j}}^{i}\right|^{2}
\end{aligned}
$$


192 Where $E_{\text {acc }}$ is cumulative squared acceleration for the total wavelet packet coefficients, $C_{j, k}^{i}$ is 193 wavelet packet amplitudes, $\mathrm{n}$ is number of wavelet packet coefficients, $E(t)$ and $E(f)$ are the 194 center of the time(temporal centroid) and frequency(spectral centroid) location of a wavelet packet

195 coefficients, respectively, $S^{2}(t)$ is temporal variance, $S^{2}(f)$ is spectral variance, $\rho(t, f)$ is 196 correlation between time and frequency of wavelet packet coefficients and $E(a)_{\operatorname{maj}}$ is mean of 197 squared amplitudes of the wavelet packet coefficients of major group. In all equations maj denotes 198 major group and min denotes minor group.

\section{2d. Finding coefficients of regression analysis of those 13 parameters (Regression analysis)}

To simulate ground motion time series, 13 parameters of model must be predicted as a function of source, path and site of future scenarios through a two-stage regression analysis approach (Joyner and Boore, 1993, 1994) with moment magnitude $\left(\mathrm{M}_{\mathrm{w}}\right)$, hypocentral distance $\left(\mathrm{R}_{\text {hyp }}\right)$, rupture distance $\left(\mathrm{R}_{\mathrm{rup}}\right)$, and average shear-wave velocity within $30 \mathrm{~m}$ depth $\left(\mathrm{V}_{\mathrm{S} 30}\right)$ as 204 predictor variables.

To obtain regression coefficient, the 13 model parameters are estimated using the maximum likelihood estimation. The functional form is used to do regression analysis is as 207 follows:

$$
Y=\alpha+\beta_{1} M+\beta_{2} \ln (M)+\beta_{3} \exp (M)++\beta_{4} \ln \left(\sqrt{{R_{h y p}{ }^{2}+h^{2}}^{2}}\right)+\beta_{5} \ln \left(V_{S 30}\right)+\eta+\sigma
$$

Except for the case of correlation, $\mathrm{Y}$ is the natural logarithm of a model parameter (for correlation $Y$ is transformed coefficient), and $\eta$ and $\delta$ are intra and interevent residuals, respectively. The parameters $\alpha$ and $\beta_{\mathrm{i}}$ are regression coefficients that must be predicted. Other details of regression analysis, can be found in the original paper. Through the source parameters, the logarithmic $\ln (M)$ term is used only for predicting $E(a)_{m a j}$ and $E_{a c c}$ because, at large magnitude, they may confront a saturation.

\section{2e. Major and Minor and Group of Wavelet Packets}

In order to simulate future ground motions of a target event, the predicted parameters must lead to distributions in time and frequency. 

different manner in distributions in time and frequency from those of small. So, the WPT coefficients were divided into two groups, Major and Minor group. Observations from the major wavelet packet coefficients demonstrate that their locations are dependent in time and frequency,

222 but free from their amplitudes. To illustrate this statistically, the squared amplitudes have exponential distributions and the locations are in the form of consistent with bivariate lognormal 224 distributions. Parameters and its characteristics and represented functional form of WPT 225 coefficients in both groups are listed in Table 2.

\section{2f. Inverse Wavelet Packet Transform}

After obtaining wavelet packet coefficients for both groups through mentioned distributions which acquired by estimated parameters calculated via regression equation and combining them, the inverse WPT is used to reconstruct time series from wavelet packets as 231 follows:

$$
x(t)=\sum_{i=1}^{2^{j}} \sum_{k=1}^{2^{N-j}} c_{j, k}^{i} \psi_{j, k}^{i}
$$

where $2^{N}$ is the number of time steps in the time series. To reconstruct the time series, another required case is the sign of the amplitudes of wavelet packet which obtained here randomly because it doesn't have an impressive effect on the ground motion characteristics.

\section{Strong Motion Data and Data Processing}

The strong motion database of Road, Housing and Urban Development Research Center (BHRC) is used for the period between 1975 and 2018. Database is comprised of 1636 events (Fig 1.c) with Mw between 3-7.5. 3828 recordings of 892 stations (Fig 1.b) with hypocentral distances less than $300 \mathrm{~km}$ are selected. We selected those events that was recorded at least 5 stations. Stations are equipped with SMA1, Guralp or SSA2 accelerometers with a sampling rate of 200 samples per second. Stations and epicentral distribution of earthquakes are shown in Figure 1.b and Figure 1.c. Figure 2.a and 2.b show Magnitude versus Repi and $\mathrm{Vs}_{30}$ versus Repi respectively. From the 3828 three-component waveforms used in this study, 1469 records are not associated with measured Vs30 data (from 504 stations), so for these records we used the estimated Vs 30 obtained by 
Najaftomaraei et al (2020). Their approach estimates $V_{S 30}$ of stations, using a normal distribution and also PDF and CDF of natural logarithm of horizontal-to-vertical ratio (H/V) of PGA and PSAs at 24 periods (388 stations).

For initial data processing, a suitable window for high quality accelerograms must be selected. In order to choose the appropriate section of waveforms, arrival times of $\mathrm{P}$ and $\mathrm{S}$ waves were determined. Considered window starts two seconds before $\mathrm{P}$ wave arrival and continues till the end of waveform. A linear trend removal was applied to the data. Low quality data with a Signal to Noise Ratio (SNR, Eq. (17)), smaller than three $(\mathrm{SNR}<3)$ were eliminated. Further data with no pre-event and even those with no $\mathrm{P}$ wave (truncated data) were not considered. Since having information about style of faulting is restricted to just some of events, effect of this parameter on regression analysis was neglected, which needs to be studied and improved.

$$
S N R=\frac{R M S \text { of Signal }}{R M S \text { of Noise }}=\frac{\sqrt{\frac{\sum Y_{i}^{2}}{n_{\text {sig }}}}}{\sqrt{\frac{\sum N_{i}^{2}}{n_{\text {Noise }}}}}
$$

Where $\mathrm{Y}$ is signal amplitudes, $\mathrm{N}$ is noise amplitudes, $\mathrm{n}_{\text {sig }}$ and $\mathrm{n}_{\text {noise }}$ define the number of samples of signal and noise respectively and RMS is the root mean square.

\section{Stochastic Simulation}

Essentially major steps given in the methodology section were followed for the simulation. In the first phase of the analysis WPT was applied to processed ground motion recordings. As an example, time, frequency, and wavelet packet coefficients at the corresponding time and frequency of an arbitrary signal are shown in Figure 4 and the same plot for the 2000/2/7 Mw:4.2 event recorded at 'Ab-bar' station recordings is shown in Figure 5. We can see the whole waveletpacket transform amplitudes of the record in this figure, large amplitudes are concentrated in about $12.5 \mathrm{~s}$ and between 3-4 Hz, as it is clear the number of small amplitudes are much further than large ones. This fact leads to the idea of dividing the amplitudes into two groups. The time and frequency nonstationary is also observable in this figure.

Then, 13 model parameters were estimated using observed time series. and regression coefficients were estimated utilizing two-stage regression analysis in Matlab. For the two-stage regression analysis, we apart the relation into two regression equations: The first one is related to intra-event 
273 effects considering distances and site conditions, and the second is related to inter-event effects

274 with the characteristics of the earthquakes (Joyner and Boore 1993,1994). To predict all

275 parameters, regression analysis was carried out using functional form of Eq.4 for all of the 3828

276 records. Figure 6 shows Major and Minor amplitudes of recordings given in Figure 5. The major

277 group of wavelet packet amplitudes are the largest, which entirely consist $70 \%$ of the total energy

278 (less than one-percent of the whole number of coefficients). The remaining packets with smaller

279 amplitudes place in the minor group. Relationship between wavelet packet coefficients and some

280 of these parameters is shown in Figure 7. In this figure $\mathrm{E}(\mathrm{t})$ is the temporal centroid, which is

281 associated with the time of the powerful part of the ground motion, $S^{2}(t)$ is temporal variance

282 related to significant duration containing $90 \%$ of the total energy, $\mathrm{E}(\mathrm{f})$ is the spectral centroid and

283 is associated with the dominant frequency, and $S^{2}(f)$ is the spectral variance related to significant

284 bandwidth that contains $90 \%$ of the total energy.

285 In the final phase, stochastic simulations at 3828 acceleration time series from 1636 earthquakes

286 utilizing the calculated stochastic time series prediction model.

287

288

\section{Results and Discussion}

289 The resulting regression coefficients are shown in Table 3. In Table 4 the correlations of total 290 residuals for each pair of model parameters have been tabulated. There can be some factors that 291 doesn't exist in the regression equation which may have influence on the model parameters 292 computed from observed ground motions. So, a correlation must be performed through the intra293 and inter-event residuals.

294 To evaluate and compare the simulated data with the observed, the parameters related to the two 295 categories (simulated and observed data) are plotted relative to each other and shown in Figure 8. 296 These parameters are the PGA and Spectral Accelerations $(\mathrm{Sa})$ at $\mathrm{T}=0.01 ; 0.06 ; 0.5 ; 1 ; 5 ; 10$ and $29720 \mathrm{sec}$, Arias intensity (Arias 1970,) and Significant duration. As shown in Figure 8, the estimated 298 parameters from the simulated data are in good agreement with the real data, indicating the 299 acceptable validity of the estimated stochastic simulation model.Fig 8.a is simulated versus 300 observed PGA, Fig 8.b is significant duration of simulated ground motion versus observed, Fig $3018 . c$ is Arias intensity of simulated ground motion versus observed, Figures: 8.d, 8.e, 8.f, 8.g, 8.h, 302 8.i and 8.j show simulated versus observed PSA at $\mathrm{T}=0.01 ; 0.06 ; 0.5 ; 1 ; 5 ; 10$ and $20 \mathrm{sec}$ 303 respectively. Generally, the model can produces the observed PGA and PSA over periods from 
0.01 to $20 \mathrm{~s}$, but for $\mathrm{T}=0.01, \mathrm{~T}=5$ and $\mathrm{T}=10 \mathrm{sec}$, data distribution around equality line $(\mathrm{y}=\mathrm{x})$ are more acceptable.

For all records, wavelet packet coefficients and resulting time series, were simulated and finally PGA, Significant duration, Arias Intensity and SA at 7 periods were extracted for both simulated and recorded ground motion. In left panels of Figure 9 -12 simulated and observed acceleration, velocity and displacement time series has been shown for tabulated earthquake in Table 5. In addition, the Fourier and response spectrum of simulated and recorded ground motions have been shown in right panel of Figures 9 -12.

In these figures, contrast of recorded and simulated acceleration time series is shown. Match between observed and simulated waveforms of acceleration, velocity and displacement are acceptable. Duration of the simulated and observed time series are similar to each other and show qualified matching. At long periods estimated PSA is larger than observed and the model overestimates it. Fourier Amplitude spectra matching at frequencies lower than about $8 \mathrm{~Hz}$ is seem to be the best.

As shown in Table 5, the magnitude of these earthquakes was considered from 4.2 to 7.3 to evaluate the validity of the estimated simulation model in a wider range of magnitudes. Also, the effect of shear wave velocity in 30 meters $\left(V_{30}\right)$, which indicates the site effect below the stations, was from 296 to $700 \mathrm{~km} / \mathrm{s}$ for the selected stations in order to evaluate the performance of the derived simulation model according to different soil effects. In addition, the epicentral distance for the mentioned stations varied from 42 to $111 \mathrm{~km}$ (Table 5).

Due to the limitations of the stochastic simulation method and the lack of consideration parameters such as slip distribution on the fault, three-dimensional velocity and attenuation model and etc., acceptable agreement between the simulated and observed acceleration, velocity and displacement can be seen in the time domain. In other side, as it is clear in figure $9-12$, there is an almost good agreement between the Fourier and response spectrum of simulated and observed time series.

\section{Conclusion}

To simulate ground motion time series, 13 statistical model parameters that extracted from wavelet packet analysis, were obtained and estimated using maximum likelihood method using recorded ground motion of BHRC database for Iran. These parameters assumed as a function of seismic 
335 properties such as earthquake magnitude, distance and Vs30 and so through a two-stage regression 336 analysis the coefficient of the regression was obtained. Intra and inter-event residuals of 337 coefficients and correlation of total residuals of those 13 parameters were also calculated. Since 338 temporal and the spectral nonstationarity can be governed by this computationally non expensive 339 method and since there are some regions in Iran that certainly mega constructions will be 340 established on in the future and also because of not having enough recorded ground motions to be 341 used in engineering purposes in that areas, time series prediction equation coefficient was obtained

342 to simulate ground motions and then a validation test was done for all records with comparing 343 simulated and recorded parameters such as PGA, Significant duration, Arias Intensity and Sa at 7 344 periods, also for four earthquake, this comparison of engineering demand parameters for recorded 345 and simulated time series showed a good consistent. Certainly because of our constraints on data 346 such as not having style of faulting, this study can be improved by inputting some other 347 seismological parameter in the model to make it more realistic.

\section{Acknowledgment}

351 We offer our sincere appreciation for BHRC to provide us the strong ground motion database. 352

\section{Conflicts of interests}

354 The authors declare that they have no known competing financial interests or personal relationships 355 that could have appeared to influence the work reported in this paper. 


\section{References}

Abrahamson, NA., Shedlock, KM. (1997) Overview. Seismological Research Letters 68(1):9-23

Abrahamson, N., Atkinson, G., Boore, D., Bozorgnia. Y., Campbell, K., Chiou, B., Idriss, IM., Silva, W., Youngs, R. (2008) Comparisons of the NGA ground-motion relations. Earthq Spectra 24(1):45-66. doi: 10.1193/1.2924363

Amiri, G. G., Shahjouei, A., Saadat, S., and Ajallooeian, M. (2011). Hybrid evolutionary-neural network approach in generation of artificial accelerograms using principal component analysis and wavelet-packet transform, J. Earthq. Eng. 15 , no. 1, 50-76.

Anderson, JG. (1997b) Nonparametric description of peak acceleration above a subduction thrust. Seismological Research Letters 68(1):86-93

Arias, A. (1970). A measure of earthquake intensity, in Seismic Design for Nuclear Power Plants, R. J. Hansen (Editor), MIT Press, Cambridge, Massachusetts, 438-483.

Atkinson, GM., Somerville, PG. (1994) Calibration of time history simulation methods. Bulletin of the Seismological Society of America 84(2):400-414

Atkinson, GM., Boore, DM (2007) Earthquake Ground-Motion Prediction Equations for Eastern North America. Bulletin of the Seismological Society of America; 97 (3): 1032. doi: https://doi.org/10.1785/0120070023

Bai, Q., Fu, L. H., Bao, W. B., Jin, S. J., \& Zhang, D. S. (2012). An Ensemble of Ground Motions Simulation Based on Discrete Stationary Wavelet Transform. Applied Mechanics and Materials, 166-169, 2408-2411. https://doi.org/10.4028/www.scientific.net/amm.166-169.2408

Baker JW., Cornell, CA. (2006) Spectral shape, epsilon and record selection. Earthquake Engineering and Structural Dynamics 35(9):1077-1095, DOI: 10.1002/eqe.571

Bommer, JJ., Alarcón JE. (2006) The prediction and use of peak ground velocity. Journal of Earthquake Engineering 10(1):1-31

Boore, DM. (1983) Stochastic simulation of high-frequency ground motions based on seismological models of the radiated spectra. Bulletin of the Seismological Society of America 73(6):1865-1894

Boore, DM. (2003) Simulation of ground motion using the stochastic method. Pure and Applied Geophysics 160(34):635-676, DOI: 10.1007/PL00012553 
Campbell, KW. (1986) An empirical estimate of near-source ground motion for a major, $\mathrm{Mb}=6.8$, earthquake in the eastern United States. Bulletin of the Seismological Society of America 76(1):1-17

Campbell, KW. (2003) Prediction of strong ground motion using the hybrid empirical method and its use in the development of ground-motion (attenuation) relations in eastern North America. Bulletin of the Seismological Society of America 93(3):1012-1033

Campbell, KW. (2007) Validation and update of hybrid empirical ground motion (attenuation) relations for the CEUS. Tech. rep., ABS Consulting, Inc. (EQECAT), Beaverton, USA, Award number: 05HQGR0032

Douglas J. (2003) Earthquake ground motion estimation using strong-motion records: A review of equations for the estimation of peak ground acceleration and response spectral ordinates. Earth-Science Reviews 61(1-2):43-104

Douglas, J., Bungum, H., Scherbaum F. (2006) Ground-motion prediction equations for southern Spain and southern Norway obtained using the composite model perspective. Journal of Earthquake Engineering 10(1):33-72 purposes, Surv. Geophys. $\mathrm{w}=4$ Tehran earthquake using a hybrid method of modal summation and finite difference. Journal of Geophysics and Engineering, 10(2), 025007. doi:10.1088/1742-2132/10/2/025007

414 Gholami, V., Hamzehloo, H., Mura, C. L., Ghayamghamian, M. R., \& Panza, G. F. (2013). Simulation of selected 415 strong motion records of the $2003 \mathrm{MW}=6.6$ Bam earthquake (SE Iran), the modal summation-ray tracing methods 416 in the WKBJ approximation. Geophysical Journal International, 196(2), 924-938. doi:10.1093/gji/ggt405

417 Hanks, TC. (1979) b values and x-c seismic source models: Implications for tectonic stress variations along active crustal fault zones and the estimation of high-frequency strong ground motion. Journal of Geophysical Research 84(B5):2235-2242

Hanks, TC., McGuire, RK. (1981) The character of high-frequency strong ground motion. Bulletin of the Seismological Society of America 71(6):2071-2095 
428

429

430

431

432

433

434

435

436

437

438

439

440

441

442

443

444

445

446

447

448

449

450

451

452

453

454

455

456

457

458

459

460

Hassani, B., Zafarani, H., \& Farjoodi, J. (2012). Stochastic Finite-Fault Simulation of 22 February 2005 (Mw 6. 4)

Zarand Earthquake (Iran), based on Dynamic Corner Frequency.

Hisada Y (2008) Broadband strong motion simulation in layered half-space using stochastic Green's function technique. Journal of Seismology 12(2):265-279, DOI: 10.1007/s10950-008-9090-6

Huang, D., Wang, G. (2015). Stochastic simulation of regionalized ground motions using wavelet packets and cokriging analysis. Earthquake Engineering \& Structural Dynamics 2015; 44:775-794. DOI:10.1002/eqe.2487.

Jackson, J., McKenzie, D. (1984), Active tectonics of the Alpine-Himalayan belt between western Tur-key and Pakistan, Geophys. J. R. Astron. Soc., 77,185 - 264

Joyner, WB., Boore, DM. (1988) Measurement, characterization, and prediction of strong ground motion. In: Proceedings of earthquake engineering \& soil dynamics II, Geotechnical division, ASCE, pp 43-102

Joyner, W. B., Boore, D. M. (1993). Methods for regression analysis of strong-motion data, Bull. Seismol. Soc. Am. 83 , no. 2, 469-487.

Joyner,W. B., Boore, D.M. (1994). Errata, methods for regression analysis of strong-motion data, Bull. Seismol. Soc. Am. 84, no. 3, 955-956.

Lee, Y., Anderson, JG., Zeng, Y. (2000) Evaluation of empirical ground-motion relations in southern California. Bulletin of the Seismological Society of America 90(6B), S136-S148

Mai, PM., Beroza, GC. (2003) A hybrid method for calculating near-source, broadband seismograms: Application to strong motion prediction. Physics of the Earth and Planetary Interiors 137(1-4):183- 199, DOI: 10.1016/S00319201(03)00014-1

Meyer, Y. (1986). Principe d'incertitude, bases hilbertiennes et algebres d'operateurs, Séminaire N. Bourbaki 662, 209-223.

Mirzaei, N., Mengtan, G., Yuntai C. (1998). Seismic source regionalization for seismic zoning of Iran: major seismotectonic provinces, J. Earthq. Pred. Res., 7, 465-495.

Najaftomaraei, M. R., Rahimi, H., Tanircan, G., Mahani, A. B., Shahvar, M. (2020). Site classification and probabilistic estimation of Vs30 for the Iranian strong-motion network. Physics of the Earth and Planetary Interiors, $308,106583$. 
Nicknam, A., Yazdani A., and Yaghmaei Sabegh, S. (2009) "Predicting probabilistic-based strong motion time series for citadel of Arg-E-Bam (South-East of Iran),'
Online], [Web of Science $®$ ], [Google Scholar]

Nilforoushan, F., Masson, F., Vernant, P. (2003) GPS network monitors the Arabia-Eurasia collision deformation in Iran. Journal of Geodesy 77: 411. https://doi.org/10.1007/s00190-003-0326-5

O lafsson, S., Remseth, S., Sigbjo“rnsson, R. (2001) Stochastic models for simulation of strong ground motion in Iceland. Earthquake Engineering and Structural Dynamics 30(9):1305-133129, no. 3, 187-220.

Pitarka, A., K. Irikura, T. Iwata, and H. Sekiguchi (1998). Three-dimensional simulation of the near-fault ground motion for the 1995 Hyogo-ken Nanbu (Kobe), Japan, Earthquake, Bull. Seismol.Soc. Am. 88, no. 2, $428-440$.

Pitarka, A., Somerville, P., Fukushima, Y., Uetake, T., Irikura, K. (2000) Simulation of near-fault strong-ground motion using hybrid Green's functions. Bulletin of the Seismological Society of America 90(3): 566-586

Power, M., Chiou, B., Abrahamson, N., Bozorgnia, Y., Shantz, T., Roblee, C. (2008) An overview of the NGA project. Earthquake Spectra 24(1):3-21, DOI: 10.1193/1.2894833

Rathje, E. M., Faraj, F., Russell, S., Bray, J.D. (2004). Empirical relationships for frequency content parameters of earthquake ground motions, Earthq. Spectra 20, no. 1, 119-144.

Rezaeian, S. (2010). Stochastic Modeling and Simulation of Ground Motions for Performance-Based Earthquake Engineering, Department of Civil and Environmental Engineering, University of California, Berkeley, California.

Rezaeian, S., Der Kiureghian, A. (2012). Simulation of orthogonal horizontal ground motion components for specified earthquake and site characteristics, Earthq. Eng. Struct. Dynam. 41, no. 2, 335-353.

Riahi, A., Sadeghi, H. and K. Hosseini. (2015) Simulation of 2003 Bam (Iran) earthquake using empirical Green's function method via very small and near-fault events, Geophysical Journal International, Volume 201, Issue 3, Pages 1264-1286, https://doi.org/10.1093/gji/ggv074

Sasaki, F., T. Maeda, and Y. Yamamoto (2003). Artificial ground motion with non-stationarity generated using the wavelet analysis, in Proc. of the 17th Structural Mechanics in Reactor Technology (SMiRT17), Prague, Czech Republic, 17-22 August 2003.

Scherbaum, F., Cotton, F., Smit, P. (2004) On the use of response spectral-reference data for the selection and ranking of ground-motion models for seismic-hazard analysis in regions of moderate seismicity: The case of rock motion. Bulletin of the Seismological Society of America 94(6):2164-2185, DOI: 10.1785/0120030147 
Scherbaum, F., Cotton, F., Staedtke, H. (2006) The estimation of minimum-misfit stochastic models from empirical ground-motion prediction equations. Bulletin of the Seismological Society of America 96(2):427-445, DOI: $10.1785 / 0120050015$

498 Silva, W., Gregor, N., Darragh, B. (1999) Near fault ground motions. Tech. rep., Pacific Engineering and Analysis, El Cerrito, USA, PG \& E PEER-Task 5.A

Soghrat, M. R., Khaji, N., \& Zafarani, H. (2011). Simulation of strong ground motion in northern Iran using the specific barrier model. Geophysical Journal International, 188(2), 645-679. doi:10.1111/j.1365-246x.2011. 05287.x Tavakoli, B., Pezeshk, S. (2005) Empirical-stochastic ground-motion prediction for eastern North America. Bulletin of the Seismological Society of America 95(6):2283-2296, DOI: 10.1785/0120050030

Trifunac, M.D., Brady, A.D. (1976). A study on the duration of strong earthquake ground motion, Bull.Seismol.Soc.Am.65, no.3,581-626.

Vahidifard, H., Zafarani, H. \& Sabbagh-Yazdi, S.R. (2017) Hybrid broadband simulation of strong-motion records from the September 16, 1978, Tabas, Iran, earthquake (M w 7.4). Nat Hazards 87, 5781.https://doi.org/10.1007/s11069-017-2753-2

511 Watson-Lamprey, J., Abrahamson, N. (2006) Selection of ground motion time series and limits on scaling. Soil 512 Dynamics and Earthquake Engineering 26(5):477-482

514 Yamamoto, Y., Baker, J.W., 2013, Stochastic Model for Earthquake Ground Motion Using Wavelet Packets. Bulletin 515 of the Seismological Society of America, 103 (6): 3044-3056. doi: https://doi.org/10.1785/0120120312

516 Zafarani, H., \& Soghrat, M. (2012). Simulation of Ground Motion in the Zagros Region of Iran Using the Specific 517 Barrier Model and the Stochastic Method. Bulletin of the Seismological Society of America, 102(5), 2031-2045. 518 doi:10.1785/0120110315

519 Zafarani, H., Vahidifard, H., \& Ansari, A. (2013). Prediction of Broadband Ground-Motion Time Histories: The Case 520 of Tehran, Iran. Earthquake Spectra, 29(2), 633-660

521 Zafarani, H., Rahimi, M., Noorzad, A., Hassani, B., \& Khazaei, B. (2015). Stochastic Simulation of Strong-Motion 522 Records from the 2012 Ahar-Varzaghan Dual Earthquakes, Northwest of Iran. Bulletin of the Seismological Society 523 of America, 105(3), 1419-1434. doi:10.1785/0120140241 


\section{$527 \quad$ List of figures}
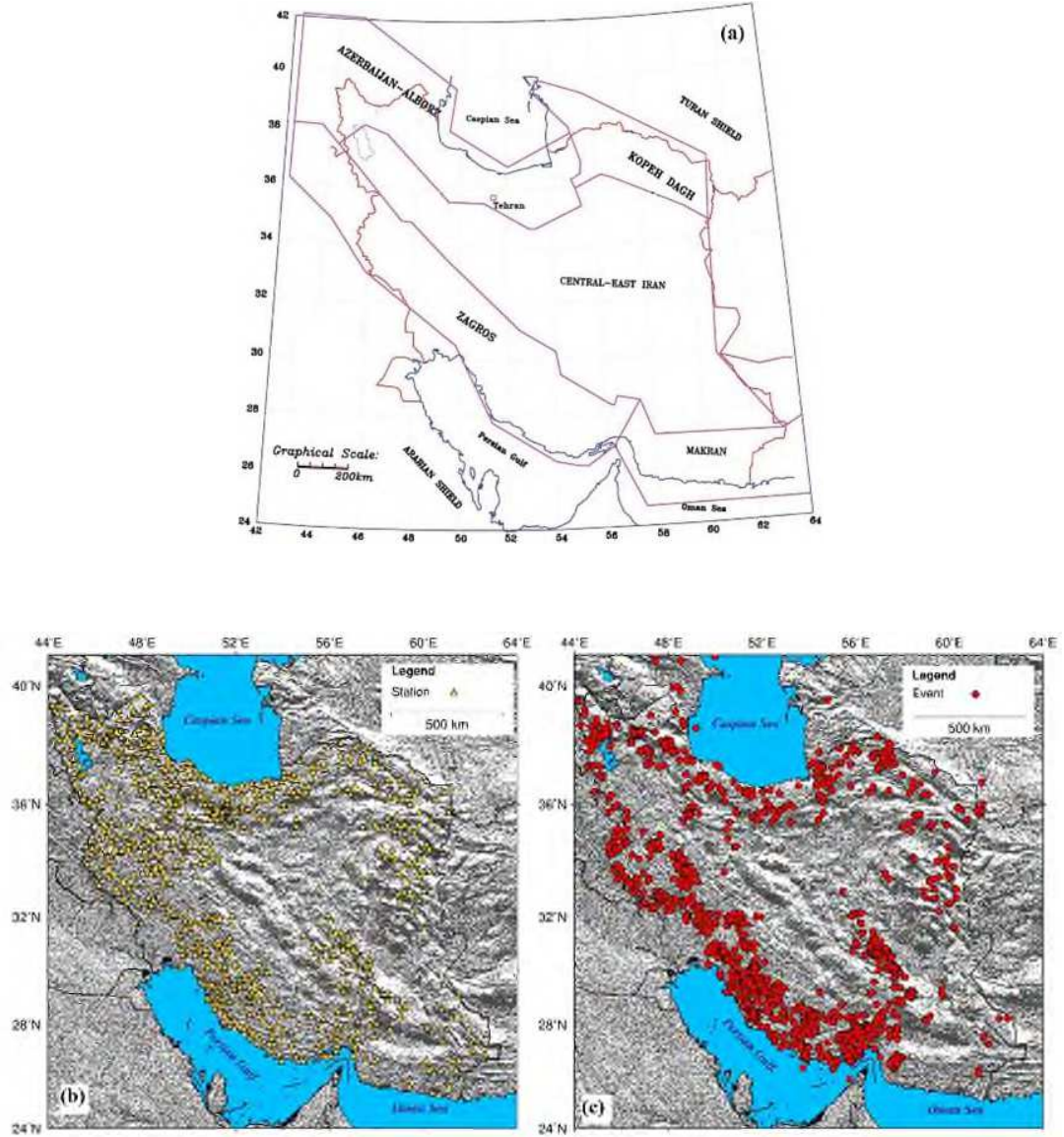

Figure 1.a) Five tectonic regions of Iran (Mirzaei et al. 1998). The distribution of the b) 892 strong motion stations and c) 1636 earthquakes studied in this research.

530 

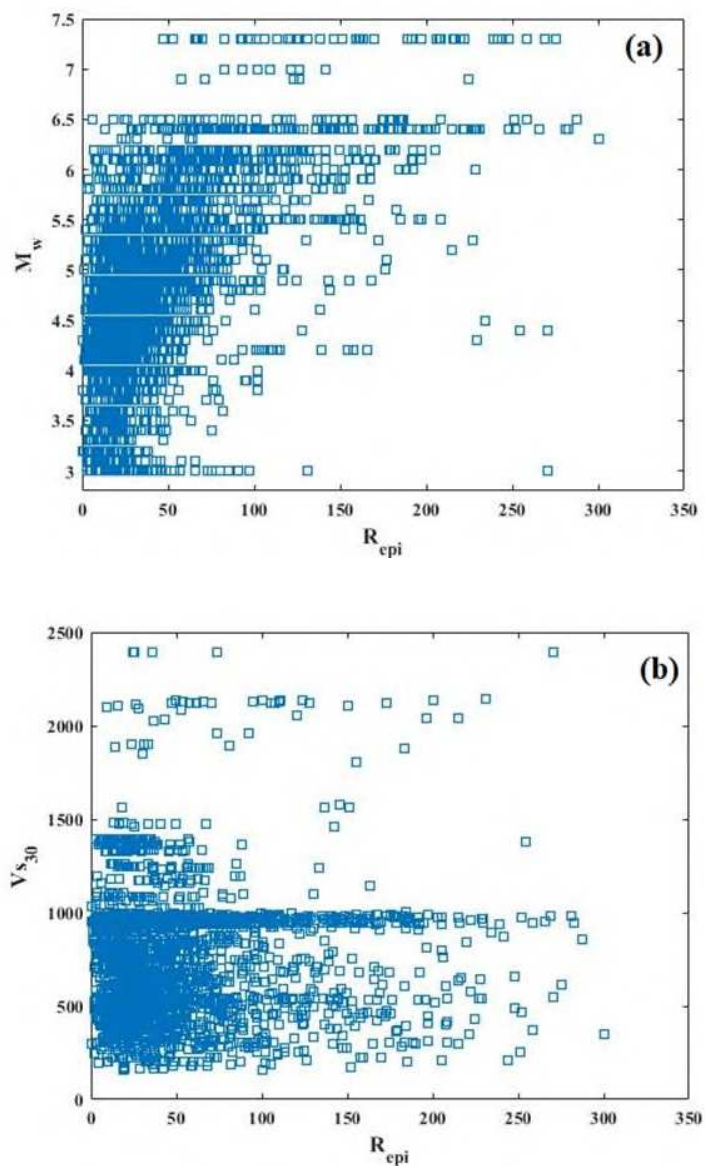

Figure 2. a) Magnitude versus epicentral distance $\left(R_{\text {epi }}\right)$ of selected earthquake b) $\mathrm{Vs}_{30}$ versus epicentral distance (Repi) 


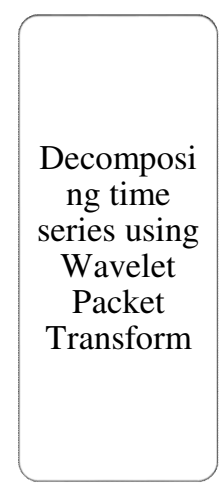

537

538

539

540
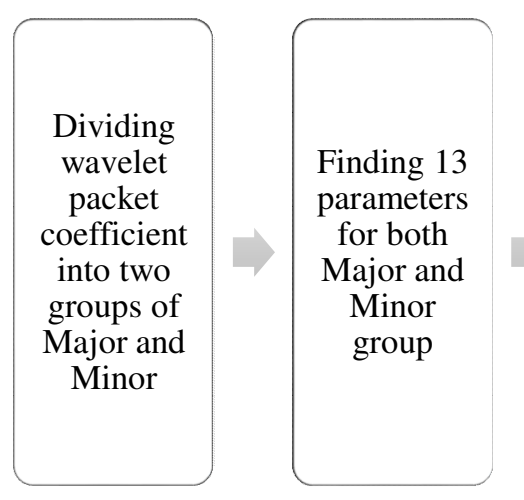

\begin{tabular}{|c|}
\hline Finding \\
WPT Coeef \\
by \\
considering \\
wavelet \\
packets of \\
future \\
scenarios \\
as \\
distribution \\
s explained \\
in related \\
section \\
\hline
\end{tabular}

Simulating time series using Inverse Wavelet Packet Transform

Figure 3. A total scheme of steps of stochastic modeling 

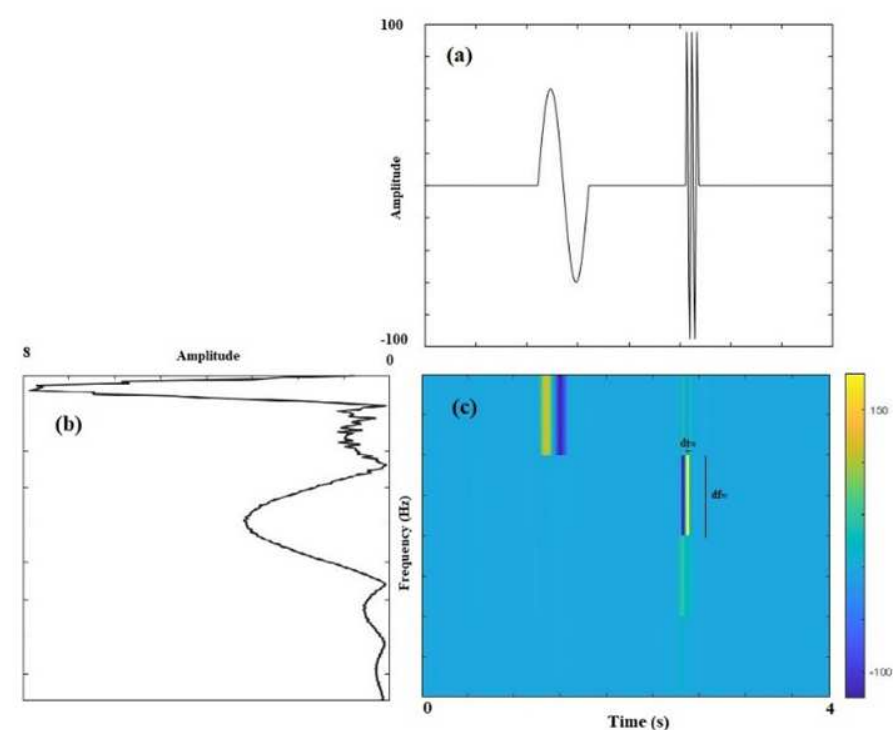

552

Figure 4. Representation of time, frequency, and wavelet domain dependency (a) Time 553 series, (b) Fourier spectrum, and (c) wavelet packet coefficients at the corresponding time and frequency

554

555

556 

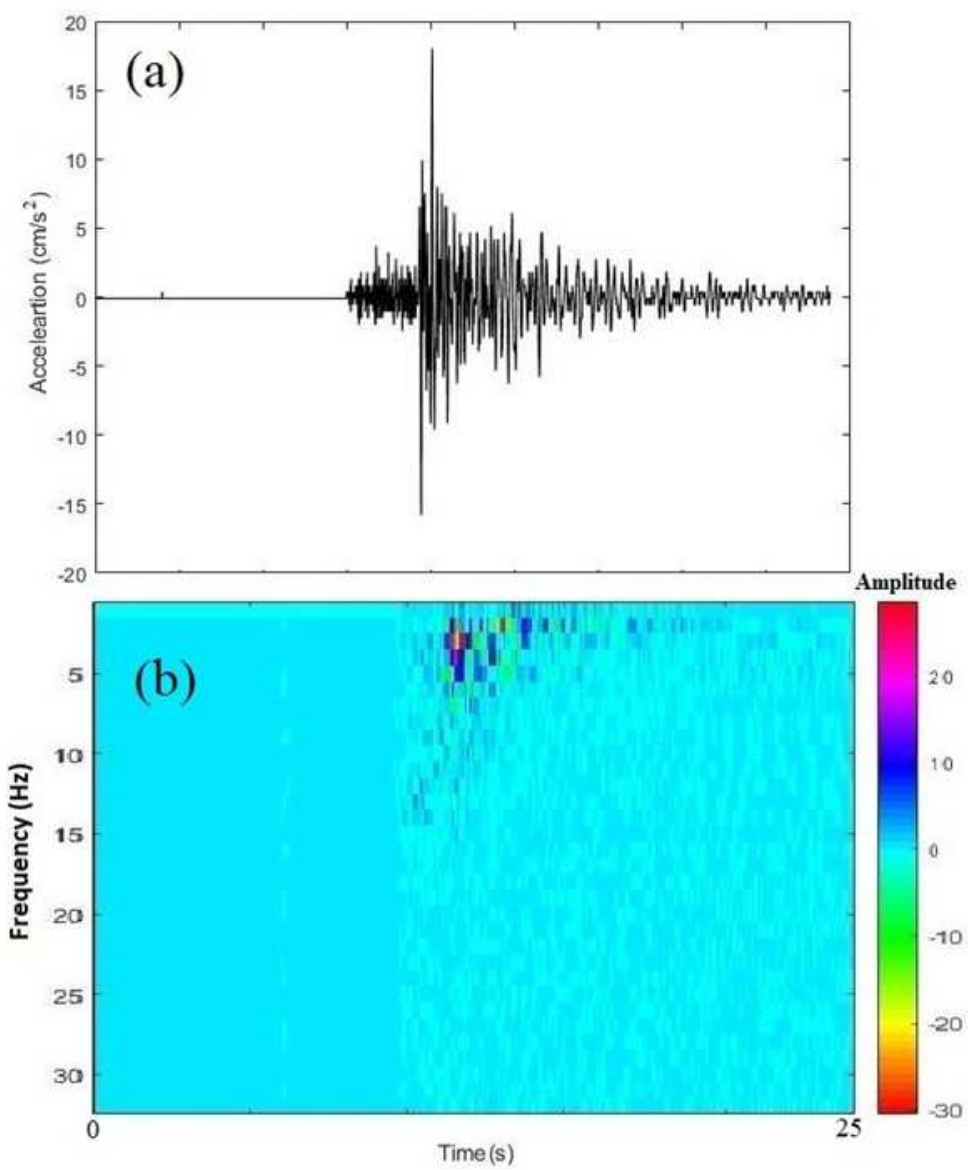

560

561

562

563

564

565

566

567

568

569

570

571

572

Figure 5. (a) Acceleration time series in EW Direction of 2000/2/7 Mw:4.2 event recorded in 'Ab-bar' station (Repi $=479 \mathrm{~km}$ ) and (b) amplitudes of its wavelet packet coefficients 

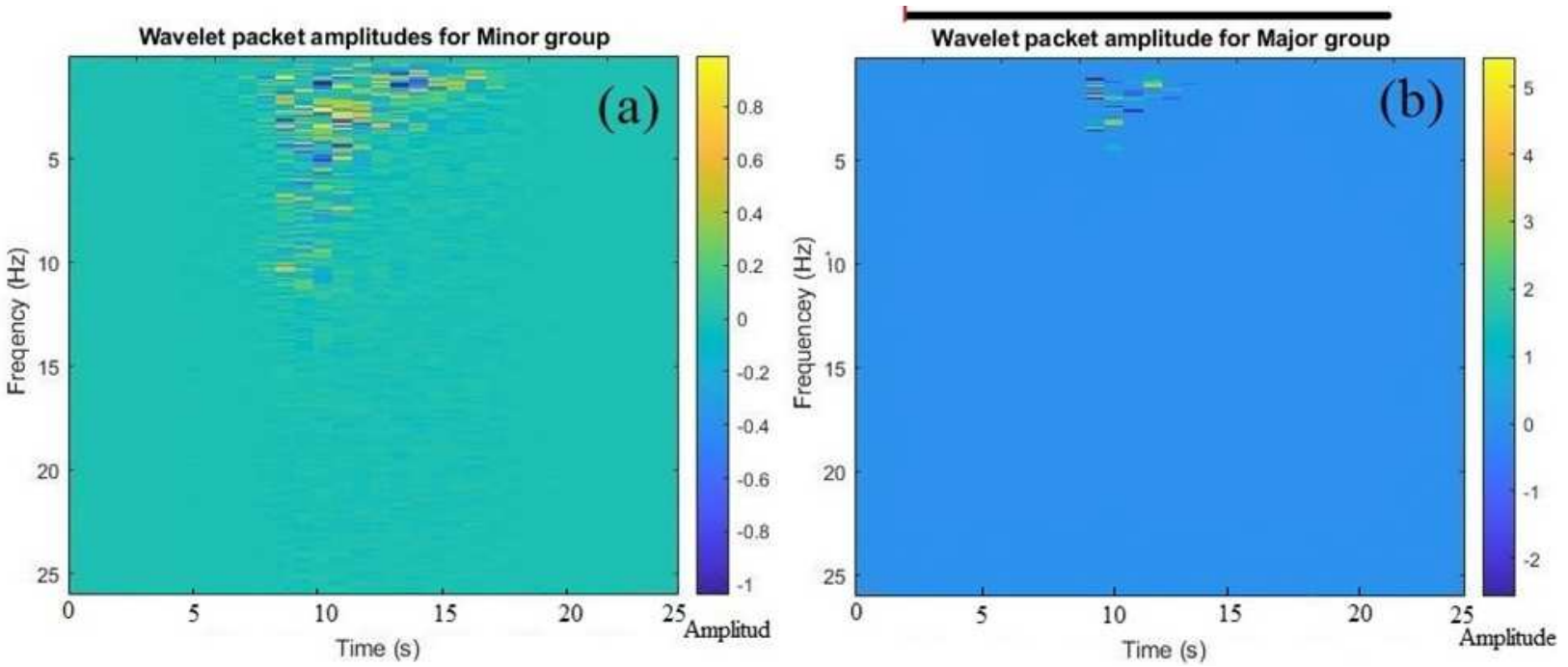


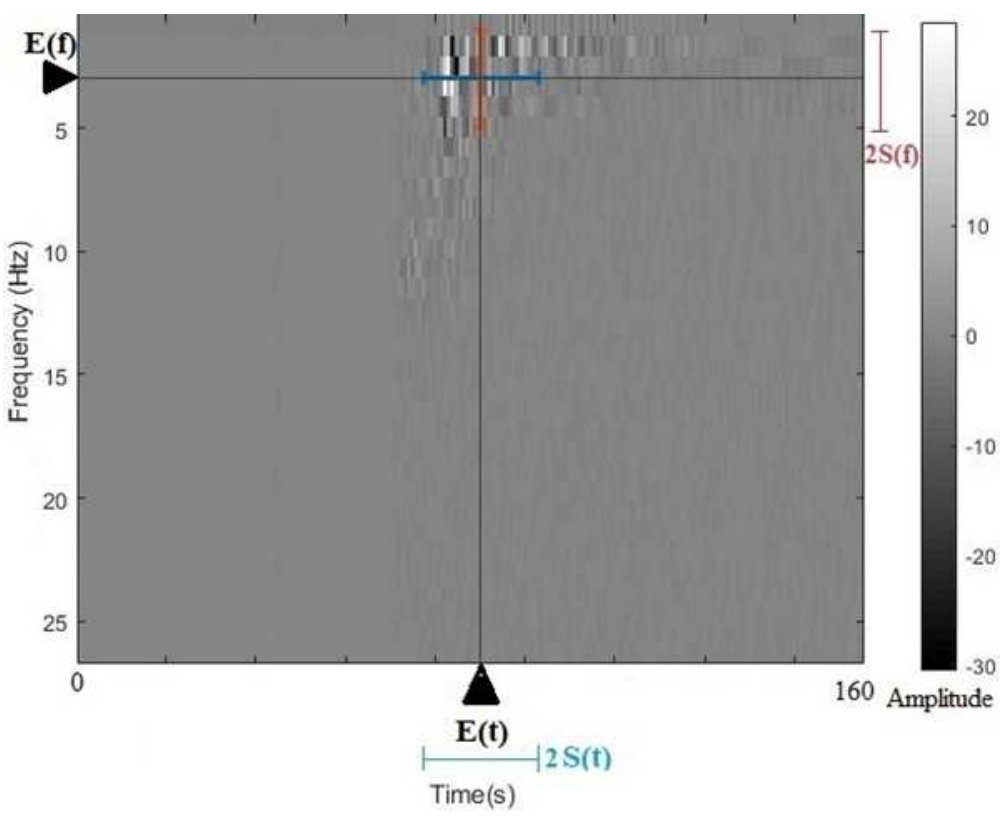

586 Figure 7. Relationship between wavelet packet coefficients and some of parameters used in regression analysis $(E(t)$ and $E(f)$ are the center of the time (temporal centroid) and frequency (spectral

588 centroid) location of a wavelet packet coefficients, respectively, $S^{2}(t)$ is temporal variance, $S^{2}(f)$ is 

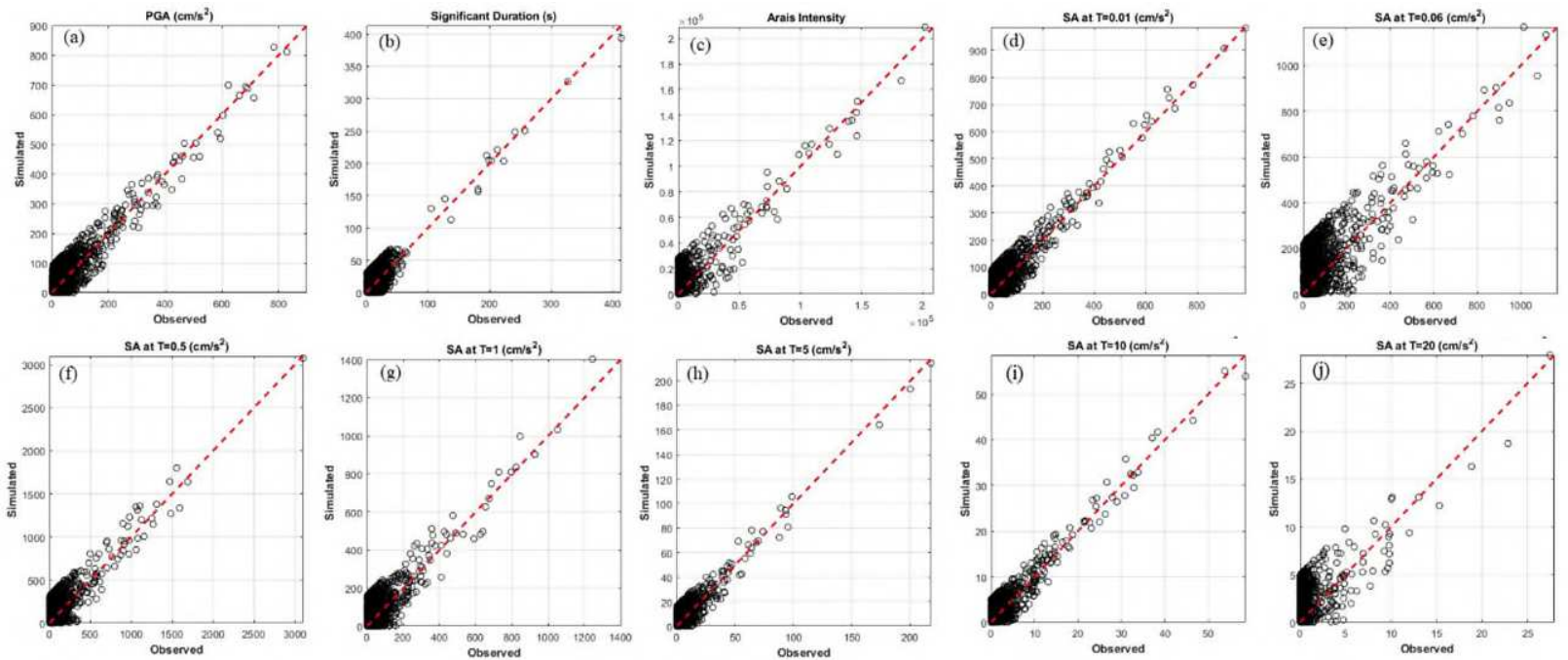

594

Figure 8. Comparison of GMIMs of simulated versus recorded strong ground motion and Spectral Accelerations at various periods a) PGA b) Significant duration c) Arias Intensity d) SA at T=0.01s e) SA at $\mathrm{T}=0.06 \mathrm{~s}$ f) $\mathrm{SA}$ at $\mathrm{T}=0.5 \mathrm{~s}$ g) $\mathrm{SA}$ at $\mathrm{T}=1 \mathrm{~s} \mathrm{~h}$ ) $\mathrm{SA}$ at $\mathrm{T}=5 \mathrm{~s}$ i) $\mathrm{SA}$ at $\mathrm{T}=10 \mathrm{~s}$ j) $\mathrm{SA}$ at $\mathrm{T}=20 \mathrm{~s}$ 
601

602

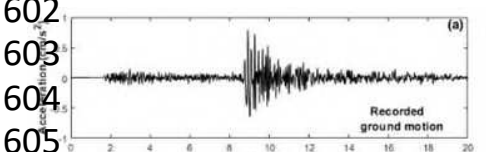

605

606

6007

600

609
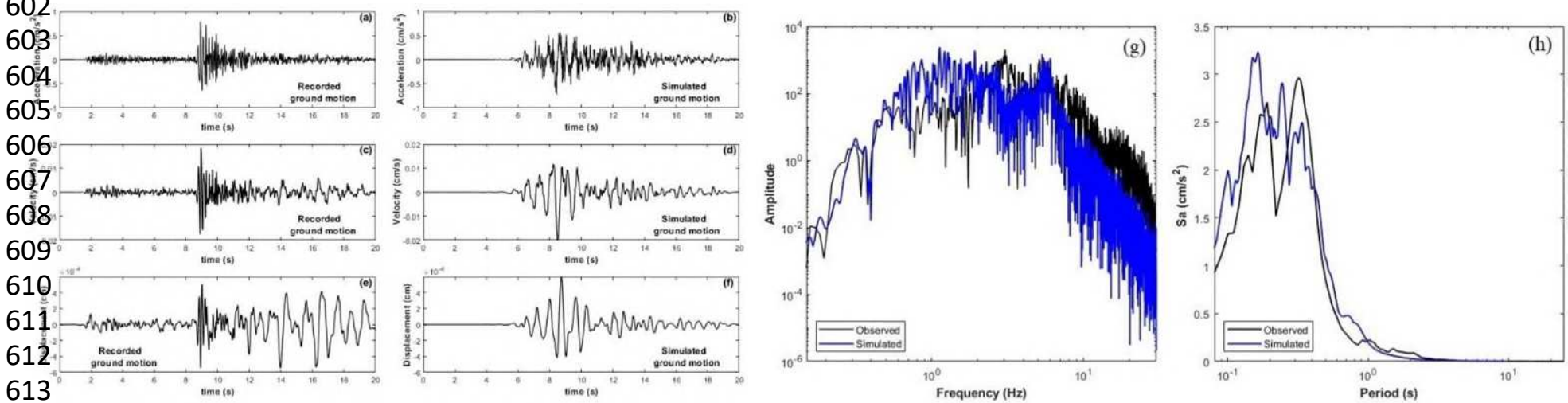

614

615 Figure 9. Recorded and simulated ground motion of the 2015/08/25 Firoozkooh Earthquake (Mw4.2) at

616 Tehran82

617 Station: (a) and (b): acceleration $\left(\mathrm{cm} / \mathrm{s}^{2}\right)$, and (c) and (d): velocity $(\mathrm{cm} / \mathrm{s})$, (e) and (f): displacement $(\mathrm{cm})$, 618 (g): Fourier Amplitude Spectrum (cm/s) (h):SA versus period for recorded and simulated ground motion, 619 respectively

620 


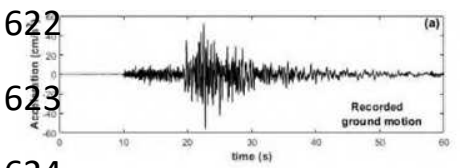

624

625

626

627

628

629

630

631

632

633

634

635

636
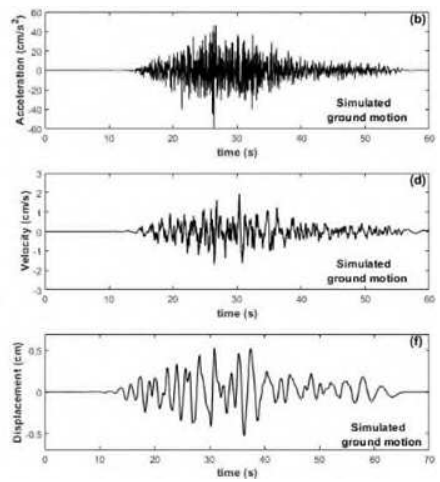

Simulated
ground motion
50
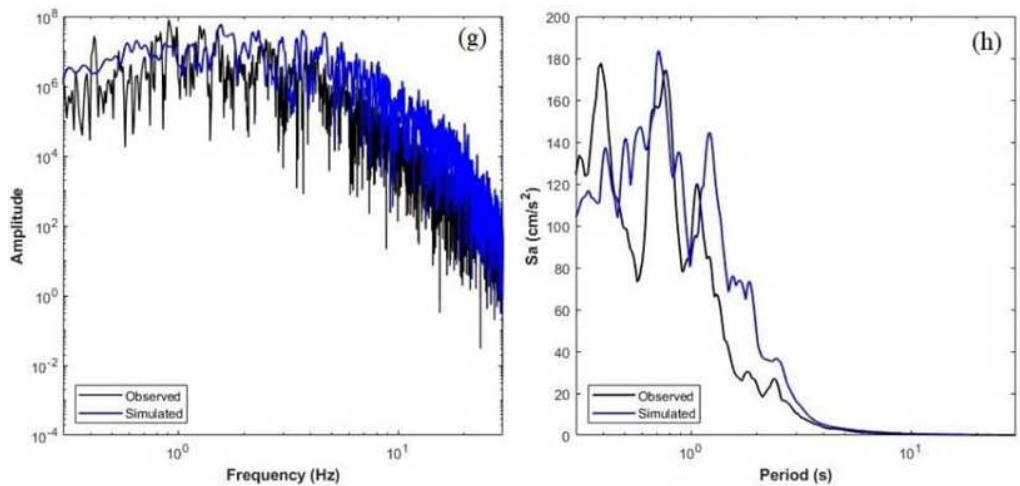

Figure 10. Recorded and simulated ground motion of the 2012/08/11 Ahar Earthquake (Mw6.1) at Meshkinshahr : (a) and (b): acceleration ( $\left.\mathrm{cm} / \mathrm{s}^{2}\right)$, and (c) and (d): velocity (cm/s), (e) and (f): displacement $(\mathrm{cm}),(\mathrm{g})$ : Fourier Amplitude Spectrum $(\mathrm{cm} / \mathrm{s})(\mathrm{h}):$ SA versus period for recorded and simulated ground

637 
639

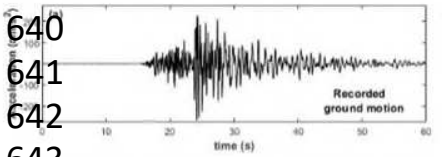

643

644

645

646 io $\quad$ is

647

648

649

650

651

652

653

654

655

656

657
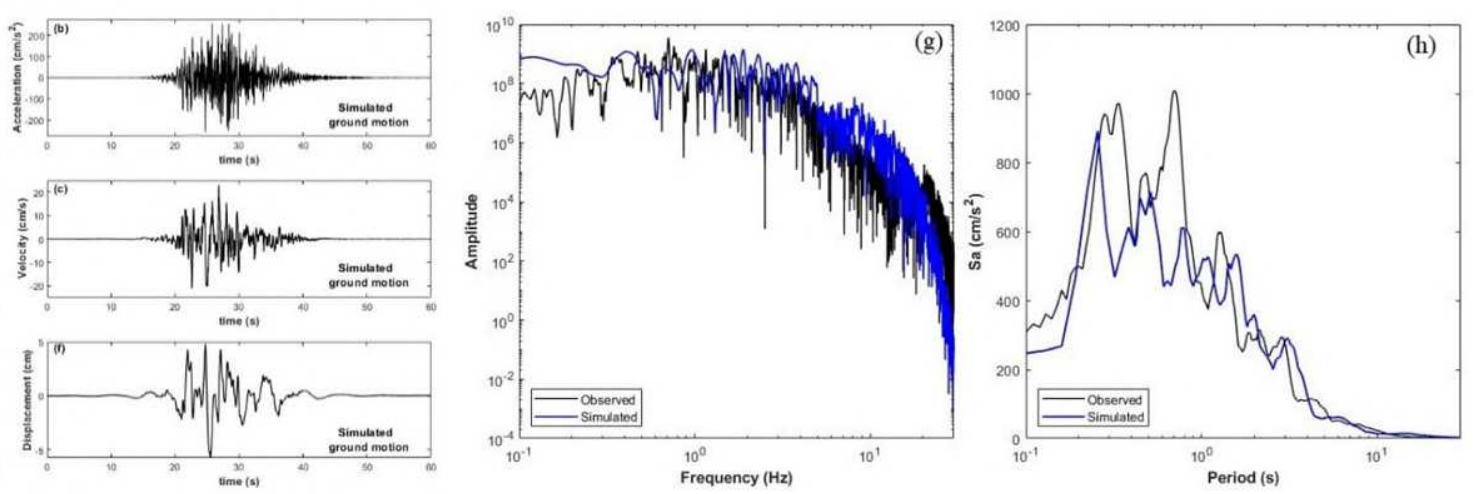

Figure 11. Recorded and simulated ground motion of the 2017/11/12 Sarpolzahab Earthquake (Mw7.3) at Ghoorsefid Station.: (a) and (b): acceleration $\left(\mathrm{cm} / \mathrm{s}^{2}\right)$, and (c) and (d): velocity $(\mathrm{cm} / \mathrm{s}),(e)$ and (f): displacement $(\mathrm{cm}),(\mathrm{g})$ : Fourier Amplitude Spectrum $(\mathrm{cm} / \mathrm{s})(\mathrm{h}):$ SA versus period for recorded and simulated ground motion, respectively. 

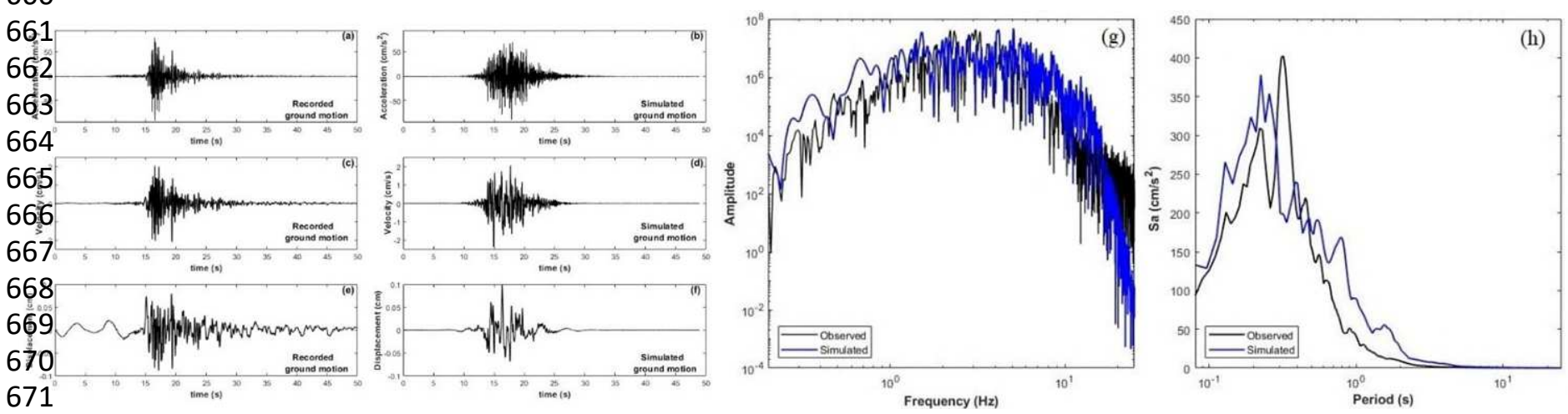

671

672 Figure 12.

673 Recorded and simulated ground motions of the 2011 /03/05 Babamonir Earthquake (Mw5.2), at Ghaemiyeh 674 station: (a) and (b): acceleration $\left(\mathrm{cm} / \mathrm{s}^{2}\right)$, and (c) and (d): velocity $(\mathrm{cm} / \mathrm{s}),(\mathrm{e})$ and (f): displacement $(\mathrm{cm})$,

675 (g): Fourier Amplitude Spectrum (cm/s) (h):SA versus period for recorded and simulated ground motion, 676 respectively.

677 
List of Tables

Table 1. Thirteen parameters that explain the time and frequency characteristics of the acceleration time series

\begin{tabular}{|c|c|c|c|c|c|}
\hline Parameter name & $\begin{array}{l}\text { Parameter } \\
\text { denotation }\end{array}$ & Group name & Parameter name & $\begin{array}{l}\text { Parameter } \\
\text { denotation }\end{array}$ & $\begin{array}{c}\text { Group } \\
\text { name }\end{array}$ \\
\hline 1. temporal centroid & $E(t)_{m a j}$ & \multirow{6}{*}{ Major group } & $\begin{array}{l}\text { 7. temporal } \\
\text { centroid }\end{array}$ & $E(t)_{\text {min }}$ & \multirow{6}{*}{$\begin{array}{l}\text { Minor } \\
\text { group }\end{array}$} \\
\hline 2. temporal variance & $S^{2}(t)_{m a j}$ & & 8. temporal variance & $S^{2}(t)_{\min }$ & \\
\hline 3. spectral centroid & $E(f)_{m a j}$ & & 9. spectral centroid & $E(f)_{\text {min }}$ & \\
\hline 4. spectral variance & $S^{2}(f)_{m a j}$ & & 10. spectral variance & $S^{2}(f)_{\min }$ & \\
\hline $\begin{array}{l}\text { 5. correlation } \\
\text { between time and } \\
\text { frequency of } \\
\text { wavelet packet } \\
\text { coefficients }\end{array}$ & $\rho(t, f)_{m a j}$ & & $\begin{array}{l}\text { 11. correlation between time } \\
\text { and frequency of } \\
\text { wavelet packet coefficients }\end{array}$ & $\rho(t, f)_{\text {min }}$ & \\
\hline $\begin{array}{l}\text { 6. mean of squared } \\
\text { amplitudes of the } \\
\text { WT coefficients }\end{array}$ & $E(a)_{m a j}$ & & $\begin{array}{l}\text { 12.Standard deviation of } \\
\text { randomness of } \\
\text { amplitude of wavelet packets }\end{array}$ & $S(\xi)$ & \\
\hline \multicolumn{2}{|c|}{ 13. cumulative squared acceleration } & $\begin{array}{c}\text { Total WT } \\
\text { coefficients }\end{array}$ & \multicolumn{3}{|l|}{$E_{a c c}$} \\
\hline
\end{tabular}


Table 2. Results of statistical surveys on WPT coefficients retrieved from Yamamoto and Baker,2013 study

\begin{tabular}{|c|c|c|c|}
\hline Group & Parameter & Characteristics & $\begin{array}{c}\text { Represented functional } \\
\text { form }\end{array}$ \\
\hline \multirow{3}{*}{ Major } & Time location & $\begin{array}{l}* \text { Dependent to frequency } \\
* \text { free from their amplitudes }\end{array}$ & $\begin{array}{l}\text { consistent with bivariate } \\
\text { lognormal distributions }\end{array}$ \\
\hline & Frequency location & $\begin{array}{c}\text { *Dependent to Time } \\
* \text { free from their amplitudes }\end{array}$ & $\begin{array}{l}\text { consistent with bivariate } \\
\text { lognormal distributions }\end{array}$ \\
\hline & squared amplitudes & $\begin{array}{l}\text { *Time and frequency are } \\
\text { free from this parameter }\end{array}$ & exponential distributions \\
\hline \multirow{3}{*}{ Minor } & Frequency and Time & Independent parameters & lognormal distribution \\
\hline & median amplitudes & $\begin{array}{c}\text { Dependent to Frequency } \\
\text { and Time }\end{array}$ & $\begin{array}{c}\text { bivariate lognormal } \\
\text { probability density function } \\
\text { (PDF) as a function of the } \\
\text { time and frequency }\end{array}$ \\
\hline & residual term & variable & $\begin{array}{l}\text { adding variability about } \\
\text { median amplitude }\end{array}$ \\
\hline
\end{tabular}


Table 3. Coefficients of the Prediction Equation

\begin{tabular}{|c|c|c|c|c|c|c|c|c|c|}
\hline & $\alpha$ & $\beta_{1}$ & $\beta_{2}$ & $\beta_{3}$ & $\beta_{4}$ & $\beta_{5}$ & $\sigma$ & $\tau$ & $\sigma *$ \\
\hline$E(t)_{\text {Major }}$ & 2.362 & 0 & 0 & -0.0002 & 0.57 & -0.21 & 0.4 & 0.29 & 0.49 \\
\hline$E(f)_{\text {Major }}$ & 0.142 & -0.003 & 0 & 0 & -0.45 & 0.23 & 0.46 & 0.33 & 0.56 \\
\hline$S(t)_{\text {Major }}$ & 1.828 & 0 & 0 & -0.0002 & 0.59 & -0.25 & 0.45 & 0.34 & 0.57 \\
\hline$S(f)_{\text {Major }}$ & -0.062 & -0.022 & 0 & 0 & -0.45 & 0.19 & 0.48 & 0.36 & 0.6 \\
\hline$\rho^{\prime} t, f$, Major & -10.936 & 0.165 & 0 & 0 & 2.38 & 0.42 & 2.6 & 5.03 & 5.66 \\
\hline$E(t)_{\text {Minor }}$ & 1.873 & 0 & 0 & -0.0002 & 0.53 & -0.21 & 0.38 & 0.28 & 0.47 \\
\hline$E(f)_{\text {Minor }}$ & -0.705 & -0.008 & 0 & 0 & -0.33 & 0.22 & 0.4 & 0.28 & 0.48 \\
\hline$S(t)_{\text {Minor }}$ & 2.591 & 0 & 0 & -0.00015 & 0.48 & -0.21 & 0.37 & 0.28 & 0.47 \\
\hline$S(f)_{\text {Minor }}$ & -0.133 & -0.007 & 0 & 0 & -0.18 & 0.17 & 0.35 & 0.26 & 0.44 \\
\hline$\rho^{\prime} t, f$, Minor & 0.318 & 0.009 & 0 & 0 & -0.05 & 0.1 & 0.3 & 0.22 & 0.37 \\
\hline$E(a)_{\text {Major }}$ & 6.613 & 0.275 & -0.76 & -0.76 & -0.15 & -0.46 & 1.75 & 1.45 & 2.27 \\
\hline$E E_{\text {acc }}$ & 10.555 & 0.122 & -0.21 & -0.207 & 0.02 & -0.57 & 1.63 & 1.35 & 2.11 \\
\hline$S(\eta)$ & 1.4 & 0 & 0 & 0 & 0 & 0 & 0.06 & 0 & 0.06 \\
\hline
\end{tabular}

693

694 
Table 4. Correlation of Total Residuals

\begin{tabular}{|c|c|c|c|c|c|c|c|c|c|c|c|c|}
\hline & $E(t)_{\text {Major }}$ & $E(f)_{\text {Major }}$ & $S(t)_{\text {Majo }}$ & $S(f)_{\text {Major }}$ & $\rho_{t, f, \text { Major }}^{\prime}$ & $E(t)_{\text {Minor }}$ & $E(f)_{\text {Mnor }}$ & $S(t)_{\text {Mino }}$ & $S(f)_{\text {Min }}$ & $\rho_{t, f, \text { Minor }}^{\prime}$ & $E(a)_{\text {Major }}$ & $E_{\text {acc }}$ \\
\hline$E(t)_{\text {Major }}$ & 1 & 0.43 & 0.89 & 0.3 & 0.05 & 0.88 & 0.36 & 0.8 & 0.24 & 0.02 & 0.11 & 0.13 \\
\hline$E(f)_{\text {Major }}$ & 0.43 & 1 & 0.49 & 0.9 & 0.13 & 0.39 & 0.73 & 0.42 & 0.5 & 0.13 & 0.2 & 0.18 \\
\hline$S(t)_{\text {Major }}$ & 0.89 & 0.49 & 1 & 0.35 & 0.08 & 0.83 & 0.37 & 0.8 & 0.25 & 0.08 & 0.12 & 0.13 \\
\hline$S(f)_{\text {Major }}$ & 0.3 & 0.9 & 0.35 & 1 & 0.18 & 0.29 & 0.71 & 0.32 & 0.5 & 0.05 & 0.21 & 0.18 \\
\hline$\rho_{t, f, \text { Major }}^{\prime}$ & 0.05 & 0.13 & 0.08 & 0.18 & 1 & 0.16 & 0.18 & 0.21 & 0.21 & -0.02 & 0.17 & 0.15 \\
\hline$E(t)_{\text {Minor }}$ & 0.88 & 0.39 & 0.83 & 0.29 & 0.16 & 1 & 0.38 & 0.97 & 0.26 & 0.07 & 0.13 & 0.14 \\
\hline$E(f)_{\text {Mnor }}$ & 0.36 & 0.73 & 0.37 & 0.71 & 0.18 & 0.38 & 1 & 0.39 & 0.82 & 0.04 & 0.3 & 0.26 \\
\hline$S(t)_{\text {Minor }}$ & 0.8 & 0.42 & 0.8 & 0.32 & 0.21 & 0.97 & 0.39 & 1 & 0.28 & 0.1 & 0.18 & 0.18 \\
\hline$S(f)_{\text {Minor }}$ & 0.24 & 0.5 & 0.25 & 0.5 & 0.21 & 0.26 & 0.82 & 0.28 & 1 & 0.02 & 0.39 & 0.36 \\
\hline$\rho_{t, f, \text { Min }}^{\prime}$ r & 0.02 & 0.13 & 0.08 & 0.05 & -0.02 & 0.07 & 0.04 & 0.1 & 0.02 & 1 & 0.12 & 0.09 \\
\hline$E(a)_{\text {Major }}$ & 0.11 & 0.2 & 0.12 & 0.21 & 0.17 & 0.13 & 0.3 & 0.18 & 0.39 & 0.12 & 1 & 0.96 \\
\hline$E_{\text {acc }}$ & 0.13 & 0.18 & 0.13 & 0.18 & 0.15 & 0.14 & 0.26 & 0.18 & 0.36 & 0.09 & 0.96 & 1 \\
\hline
\end{tabular}

699

700

701 
Table 5. Properties of records in Figure 9-12

\begin{tabular}{|c|c|c|c|c|c|c|c|c|}
\hline $\begin{array}{c}\text { Record } \\
\#\end{array}$ & $\begin{array}{c}\text { Earthquake. } \\
\text { name }\end{array}$ & $\begin{array}{c}\text { Date } \\
\text { year/month/day }\end{array}$ & Mw & $\begin{array}{c}\text { Record } \\
\text { Id }\end{array}$ & $\begin{array}{c}\text { PGA } \\
(\mathbf{g} \%)\end{array}$ & $\begin{array}{c}\text { Epicentral } \\
\text { distance } \\
(\mathbf{k m})\end{array}$ & $\begin{array}{c}\text { Station } \\
\text { name }\end{array}$ & $\begin{array}{c}\text { Vs30 } \\
(\mathbf{m} / \mathbf{s})\end{array}$ \\
\hline 1 & Firoozkooh & $2015 / 08 / 25$ & 4.2 & 6587 & 0.99 & 111 & Tehran82 & 296 \\
\hline 2 & Ahar & $2012 / 08 / 11$ & 6.1 & 5602 & 57 & 72 & Meshkinshahr & 700 \\
\hline 3 & Sarpolzahab & $2017 / 11 / 12$ & 7.3 & $\begin{array}{c}7377- \\
01\end{array}$ & 270 & 46 & Ghoorsefid & 403 \\
\hline 4 & Babamonir & $2011 / 03 / 05$ & 5.2 & $\begin{array}{c}5210- \\
01\end{array}$ & 94 & 42 & Ghaemiyeh & 617 \\
\hline
\end{tabular}

703

704 